\title{
IMPACT OF CERTAIN FRUIT SEED KERNELS ON Meloidogyne incognita INFECTING OKRA UNDER GREENHOUSE CONDITIONS.
}

Refaei, A. R.

Nematology Res. Unit, Agricultural Zoology Dept., Fac. Agric., Mansoura Univ., Egypt.

\begin{abstract}
A greenhouse experiment was conducted to investigate the influence of three fruit seed kernels viz: apricot, peach and plum either fresh or dry at three doses of 1 , 2 , and $4 \mathrm{gm} /$ pot in comparison with oxamyl on okra plant growth response to the infection of Meloidogyne incognita as well as its root galling and eggmasses number. Results indicated that as the dose of each seed kernel applied either fresh or dry raised from one to four grams per okra seedling, plant growth parameters obviously ameliorated as well as root galling and reproduction of M.incognita reduced. Among the tested fruit seed kernels, fresh peach kernel at $4 \mathrm{gm} /$ pot achieved the highest increase percentage in total plant fresh weight (157.9\%), shoot dry weight $(182.1 \%)$ followed by plum (152.3 \& 171.4\%), and then apricot (110.6 \& 110.7\%), respectively, comparing to nematode alone. Similar results was only obtained by dried peach powder (4 gm / pot) (181.8 and 135.7\%) for the same plant characters. Oxamyl showed intermediate values of percent increase in plant growth parameters. The dose of one gram per pot of dried peach powder surpassed other treatments of apricot and plum even oxamyl with increase percentage value of $111.7 \%$, for plant fresh weight. Moreover, plant received tested fresh seed kernels showed better performance in controlling M.incognita on okra than did the dried powder ones. Oxamyl as a nematicide surpassed all tested materials in suppressing number of root galls and eggmasses with values of $100 \%$ each. However, among the tested seed kernels the apricot fresh kernel at $4 \mathrm{gm} /$ pot gave the highest percent reduction in numbers of root galls and eggmasses (95.8 \& 100\%), followed by apricot dry powder for only root galling (91.3\%), then peach either dry or fresh kernels $(90.3 \& 100 \%)$ each, whereas, values of plum fresh kernel content were on par with those of peach $(90.3 \& 100 \%)$ comparing to nematode alone.
\end{abstract}

Keywords: Apricot, peach, plum seed kernel powders, okra, Meloidogyne incognita, oxamyl.

\section{INTRODUCTION}

Management of plant parasitic nematodes by certain organic matters i.e. plant products, animal manures and / or other sources is quite well known. Such procedure is highly recommended by several nematologistis within most countries to minimize the environmental pollution caused by nematicides and their hazards. However, the regular addition of such organic matters to the soil resulted always in the proliferation of the growing plants. The safety of such materials and its low cost is one of its advantages. Moreover, many researchers reported that organic matters affect nematode population in two different ways, directly by possessing nematicidal properties during its degradation (Sitaramaiah and Singh, 1978), or indirectly by enhancing the development of nematode natural enemies (Errico and Maio, 1980). Meanwhile, the addition of different parts of certain plant species, especially, its fresh or dry product, reduced nematode densities and 
Refaei, A.R.

ameliorate the growth of treated plants due to the nematicidal potential of these plants i.e. Azadirachta indica, Melia azadirachta, Asparagus spp., Ricinus communis, Lantana indica, Eucalyptus restrate, Eucalyptus spp. and Tagetes erecta (Akhtar and Alam, 1989; Montasser, 1991; Farahat et al., 1994; Latif et al., 1999; Khalil, 2000 and Refaei et al., 2008).

Ammonia, nitrites, phenols, hydrogen sulfide, organic acids and wide range of volatile substances are among the chemicals produced during the decomposition of plant residues and affected nematode reproduction. However, the presence of high concentrations of low molecular weight acetic, propionic, butyric, isovaleric and valeric fatty acids as well as reasonable fractions of phenol and hydrogen sulfide in such organic matter clearly proved to be highly nematotoxic (Badra et al., 1979).

It is well known that Egyptian fruit seeds of apricot, peach and plum (Fam: Rosaceae) are withdrawed as wastes which usually increase the environmental pollution. However, literature reports revealed that kernels of such stone fruits contain several fatty acids, aliphatic acid and esters as well as benzaldehyde and its derivatives (Schneider, 1985; Picuric-Jovanovic \& Milovanovic, 1993 and Someya, et al., 2006). Meanwhile, such chemical compounds were recorded from certain oil-seed-cakes i.e. garlic which exhibited antibacterial, antifungal, insecticidal and nematicidal activities (Guilt et al., 1993 and Rodriguez-Kabana, 2000). Information about the utilization of such stone fruit seed kernels i.e. apricot, peach or plum as dried powders or fresh kernel contents in arresting nematode pests is lacking.

Therefore, this investigation is carried out to determine the effect of dried seed kernel powders or fresh seed kernel contents of three fruit seeds namely apricot, peach and plum in comparison with oxamyl on root galling and eggmasses of Meloidogyne incognita infecting okra plants and their role on host growth response under greenhouse conditions.

\section{MATERIALS AND METHODS}

\section{- Nematode inoculum:}

Fresh hatched second-stage juveniles $\left(\mathrm{J}_{2}\right)$ of the root-knot nematode $M$. incognita were obtained from a pure culture established from a single eggmass that previously identified according to the characteristics of its perineal pattern (Taylor and Sasser, 1978), maintained and propagated on coleus plants, Coleus blumei on a bench in the greenhouse of Nematology Research Unit, Faculty of Agriculture, Mansoura University, Egypt, where this work was done. Sufficient inoculum of $M$. incognita $\left(\mathrm{J}_{2}\right)$ was extracted from soil by sieving and modified Baermann- technique (Goodey, 1957).

- Nematicide:

Oxamyl (Vydate 24\% L), Methyl - N'N'- dimethyl-N \{(methylcarbamyl)oxy\}-1-thiooxamidate) was used at the recommended dose of $0.3 \mathrm{ml} /$ pot.

\section{- Preparation of fruit seed kernels:}

Egyptian fruit seeds of apricot, (Prunus armeniaca), peach ( $P$ persica), and plum ( $P$. domestica) were collected as wastes and divided into 
two groups. The kernels of the first group of fruit seeds were separated by hammer, grinded and used as fresh kernels, while, seeds of second group were dried into an oven at $70{ }^{\circ} \mathrm{C}$ for $24 \mathrm{~h}$, then their kernels were separated, followed the previous way and used as dried powders both at the tested doses of 1, 2 and $4 \mathrm{gm}$ / pot according to the design of the experiment.

In order to study the effect of such fruit kernels in comparison with oxamyl on $M$. incognita infecting okra (Abelmoschus esculentus L.), pot experiment was conducted under greenhouse conditions. In this experiment sixty three plastic pots $10 \mathrm{~cm}$-diameter filled with steam-sterilized sandy: loam soil (1:1)(v:v) were planted with three seeds of okra cv. Hybrid Dokki-2 / pot, irrigated as needed and then thinned at one seedling / pot after three weeks. Sixty seedlings were then separately inoculated with 1000 second stage juveniles $\left(\mathrm{J}_{2}\right)$ of $M$. incognita and the dose of each fruit type seed kernel either fresh or dry was added to each pot around seedling at the time of nematode inoculation, whereas, oxamyl at the recommended dose $(0.3$ $\mathrm{ml} / \mathrm{pot}$ ) was separately added to three pots at the same time of nematode inoculation. Three seedlings were left free of nematode $(\mathrm{N})$ and untreated that served as healthy plants (Ck). Each treatment was replicated three times. Treatments were as follows:

1. Fresh seed kernel of apricot (1 gm),

2. Fresh seed kernel of apricot $(2 \mathrm{gm})$,

3. Fresh seed kernel of apricot (4 gm),

4. Fresh seed kernel of peach $(1 \mathrm{gm})$,

5 . Fresh seed kernel of peach $(2 \mathrm{gm})$,

6. Fresh seed kernel of peach $(4 \mathrm{gm})$,

7. Fresh seed kernel of plum (1 gm),

8. Fresh seed kernel of plum ( $2 \mathrm{gm})$,

9. Fresh seed kernel of plum ( $4 \mathrm{gm})$,

10. Dried seed kernel of apricot (1 gm),

11. Dried seed kernel of apricot $(2 \mathrm{gm})$,

12. Dried seed kernel of apricot (4 gm),

13. Dried seed kernel of peach ( $1 \mathrm{gm})$,

14. Dried seed kernel of peach (2 gm),

15 Dried seed kernel of peach (4 gm),

16. Dried seed kernel of plum (1 gm),

17. Dried seed kernel of plum (2 gm),

18. Dried seed kernel of plum (4 gm),

19. Oxamyl $(0.3 \mathrm{ml} / \mathrm{pot})$,

20. $\mathrm{N}$ alone and

11. Plants free of $\mathrm{N}$ and untreated (Ck).

Pots were arranged in a randomized complete block design on a greenhouse bench and maintained at $19 \pm 5^{\circ} \mathrm{C}$. Plants were irrigated and protected by conventional pesticides against mites and insects as needed. Forty five days after nematode inoculation, plants were harvested and root of each pot was gently rinsed with tap water to remove adhering soil particles. Length and fresh weight of each shoot and root system, as well as shoot dry weight were determined and recorded. Numbers of galls and eggmasses of $M$. incognita per each root system of okra were also counted and recorded. 
Refaei, A.R.

Root gall index (RGI) and eggmasses index (El) were estimated according to the scale given by Taylor and Sasser,(1978) as follows $\therefore: 0=$ no galls or eggmasses, $1=1-2 ; 2=3-10 ; 3=11-30 ; 4=31-100$ and $5=$ more than 100 galls or eggmasses per root system of okra plant.

Statistically, the obtained data were subjected to analysis of variance (ANOVA) (Gomez and Gomez, 1984) followed by Duncan's multiple range test to compare means (Duncan, 1955).

\section{RESULTS AND DISCUSSION}

Data in Tables (1 \& 2) represent the effect of apricot, peach and plum seed kernel content either fresh or dry at three doses of 1,2 or $4 \mathrm{gm} /$ pot in comparison with oxamyl at the recommended dose $(0.3 \mathrm{ml} / \mathrm{pot})$ on plant growth of okra infected with $M$. incognita as well as root galling and nematode reproduction under greenhouse conditions at $19 \pm 5^{\circ} \mathrm{C}$. Results indicate that all tested materials obviously ameliorated plant growth parameters with various degrees. In general, it is evident that as the fruit seed kernel doses increased from one up to four grams per seedling, plant growth parameters were also increased (Tables1\&2). For instance, plant growth showed values ranged between 30.8 to $76.2 \%, 51.1$ to $110.6 \%$, and 42.9 to $110.7 \%$ for plant length, total plant fresh weight and shoot dry weight in the case of fresh apricot kernel. Likewise, similar trend was noticed with plum and peach fresh contents, where peach seed kernel at dose of $4 \mathrm{gm} /$ pot achieved the highest increase percentage in total plant fresh weight (157.9\%) and shoot dry weight $(182.1 \%)$, followed by plum kernel content with values of 152.3 and $171.4 \%$ then apricot kernel content $(110.6 \& 110.7 \%)$ for the same plant criteria, respectively, compared to nematode alone,. However, fresh kernel treatment of apricot at $4 \mathrm{gm} /$ pot exceeded both plum and peach fresh kernels in value of plant length $(76.2 \%)$ (Table 1). Meanwhile, similar trend was recorded with pots treated with dry powders of the same fruit seed kernels at similar doses per pot for the tested plant growth parameters of okra plants (Table 2). For instance, the highest values of percentage increase for total plant fresh weight and shoot dry weight at dose of $4 \mathrm{gm} /$ pot were accomplished by peach powder (181.8 \& 135.7\%), followed by apricot dry powder (85.2 \& $125.0 \%)$, then plum powder (77.6 \& 50.0\%), respectively, (Table 2). Whereas the lowest values of percentage increase for both plant characters were detected by $1 \mathrm{gm} /$ pot treatments of apricot powder ( $28.8 \& 17.9 \%$ ) or plum powder ( $42.4 \& 25.0 \%$ ) comparing to nematode alone (Table 2 ). It is worthy to note that peach seed kernel powder at $1 \mathrm{~g} /$ pot gave the highest percent increase when compared with other treatments of $(1 \mathrm{gm} / \mathrm{pot})$ for both plant characters either applied as fresh kernel or dry kernel powder which were amounted to $65.5 \& 71.4 \%$, for fresh kernel content or $111.7 \& 78.6 \%$, for dry powder respectively, (Tables 1\&2). Similar results were obtained for plant length in the case of dry powder treatments of all fruit seeds tested at $4 \mathrm{gm}$ /pot which recorded to be in descending order $76.8,65.6$ and $61.9 \%$ for plum, apricot and peach, respectively(Table 2). 
J. Agric. Sci. Mansoura Univ., 34 (3), March, 2009

$\mathrm{T} 1-2$ 
Refaei, A.R.

Meanwhile, oxamyl surpassed most tested components in improving plant growth especially, the dose of one gram of both type of applications of the three fruit seed kernels except that of peach dry powder where the oxamyl values of increase percentage were amounted to $61.9,101.5$ and $57.1 \%$ for plant length, total plant fresh weight and shoot dry weight, respectively, comparing to nematode alone (Tables1\& 2). Moreover, plants free of nematodes and receiving non of the tested materials showed reasonable percentage of increase in total plant fresh weight, shoot dry weight and plant length with values of $11.7,21.4$ and $23.1 \%$, respectively, comparing to nematode alone (Tables 1 \&2).

Data presented in Table (3) reveal that all tested materials showed protection performance in okra plant against nematode infection in terms of reduction percentage of number of galls and eggmasses on okra roots. It was clear that number of galls as well as eggmasses were significantly affected by all seed kernel contents either fresh or dry at their tested doses of the products of the three different fruits under study. As the dose of each seed kernel content of apricot, plum and peach applied either fresh or dry raised from one up to four $\mathrm{gm} / \mathrm{pot} / \mathrm{okra}$ seedling, the reduction percentage of root galling and eggmasses of $M$. incognita were increased. In general, plant received doses of fresh seed kernel of the tested fruits showed better performance in controlling $M$. incognita than did the dried powder ones. Oxamyl as a nematicide surpassed all tested materials in suppressing number of root galls and eggmasses with values of $100 \%$ each. However, among the tested kernels at $4 \mathrm{~g} /$ pot, apricot fresh kernel gave the highest values in suppressing root galling (95.8\%) and eggmasses (100\%), followed by apricot dry powder for root galling only (91.3\%), then peach either dry or fresh with values of $90.3 \& 100 \%$ for each type of application, whereas, plum fresh kernel values was on par with peach ones $(90.3 \& 100 \%)$, respectively as compared to nematode alone (Table 3 ). Promising results were noticed among tested materials where the lowest indices for nematode criteria were achieved by fresh and dry apricot kernels at $4 \mathrm{gm} /$ pot $(1.0 ; 1.5)$ for root gall index and (0.0\& 0.5$)$ for eggmass index; and oxamyl $(0.0 \& 0.0)$, respectively as compared to nematode alone (4.0\&2.0) (Table 3).

Apparently results of the present work indicated that tested seed kernels of apricot, peach and plum applied either fresh or dry directly suppressed root galling and eggmasses number of $M$. incognita and ameliorated okra plant growth parameters at all tested doses, since apricot products exhibited antimetabolites and antimicrobial activities (Someya et al., 2006). Literature reports revealed that seed kernel of apricot has iron and amygdaline, a plant compound that contains sugar and produces cyanide that can be used as cancer drug according to Someya et al., (2006), who reported that apricot kernel extract effectively suppressed the metabolism of Corynebacterium xerosis. Meanwhile, peach kernel oil contains vitamin $\mathrm{E}$ and up to $42 \%$ fatty acids i.e. palmitic acid (4-7\%), oleic acid (55-70\%) and linoleic acid (17-30\%), whereas, apricot kernel oil contains the same fatty acids i.e. oleic acid (55-70\%), linoleic acid (20-35\%), palmitic acid (3-6\%) plus traces of stearic acid and eicosenoic acid. Analysis of plum kernel oil by gas chromatography-mass spectrometry (GC-MS) indicated a complex 
composition, consisting of fifty or more components,including n-alkanes, aliphatic acids and esters, cycloalkenes and aromatics such as furans, phenols, alkylbenzenes, benzoic acid and esters, benzaldehyde and its derivatives and benzyl alcohol. Benzaldehyde and benzyl alcohol are the major volatiles identified (Picuric-Jovanovic and Milovanovic,1993). They also said that the main volatile components in plum kernel are benzaldehyde and benzl alcohol in addition, a possible explanation for the formation of benzaldehyde could be amygdaline hydrolyses under the conditions employed in aqueous enzymatic extraction. This cyanogenic glycoside has been found in the kernel of most fruits belonging to the family Rosaceae (Schneider, 1985). It is well known that all of those chemical compounds showed nematicidal activities against such target nematode (Anke and Stadler, 1995).

Table 3: Impact of seed kernels of three different fruits applied either fresh or dry at three doses in comparison with oxamyl on number of galls and eggmasses of Meloidogyne incognita infecting okra under greenhouse conditions.

\begin{tabular}{|c|c|c|c|c|c|c|c|}
\hline \multirow{3}{*}{ Fruit kernels } & \multirow{3}{*}{$\begin{array}{c}\text { Doses } \\
(\mathrm{gm})\end{array}$} & \multicolumn{6}{|c|}{${ }^{*}$ Nematode parameters } \\
\hline & & $\begin{array}{l}\text { No. of } \\
\text { galls }\end{array}$ & $\begin{array}{c}\text { Reduction } \\
\%\end{array}$ & $\begin{array}{c}\star \star * \\
\text { RGI }\end{array}$ & $\begin{array}{c}\text { No. of } \\
\text { eggmasses }\end{array}$ & $\begin{array}{c}\text { Reduction } \\
\%\end{array}$ & $\begin{array}{c}\star \star \star \star \\
\text { El }\end{array}$ \\
\hline & & \multicolumn{6}{|c|}{ Fresh kernel content } \\
\hline \multirow[t]{3}{*}{ Apricot } & 1 & $7.70 \mathrm{~d}$ & 75.2 & 2 & $1.33 c d$ & 63.8 & 1 \\
\hline & 2 & $3.67 f g$ & 88.1 & 2 & 1.00de & 72.8 & 1 \\
\hline & 4 & $1.30 \mathrm{gh}$ & 95.8 & 1 & $0.00 f$ & 100 & 0 \\
\hline \multirow[t]{3}{*}{ Peach } & 1 & $23.30 \mathrm{~b}$ & 24.8 & 3 & $0.00 f$ & 100 & 0 \\
\hline & 2 & $4.30 f$ & 86.1 & 2 & $0.00 f$ & 100 & 0 \\
\hline & 4 & $3.00 \mathrm{fg}$ & 90.3 & 2 & $0.00 f$ & 100 & 0 \\
\hline \multirow[t]{3}{*}{ Plum } & 1 & 5.30def & 82.9 & 2 & $2.33 b$ & 36.5 & 2 \\
\hline & 2 & $5.00 \mathrm{ef}$ & 83.9 & 2 & 0.33 ef & 91.0 & 0.5 \\
\hline & 4 & $3.00 \mathrm{fg}$ & 90.3 & 2 & $0.00 f$ & 100 & 0 \\
\hline \multicolumn{8}{|c|}{ Dried kernel powder } \\
\hline \multirow[t]{3}{*}{ Apricot } & 1 & $8.7 c d$ & 71.9 & 2 & 0.67 def & 81.7 & 0.5 \\
\hline & 2 & 7.3de & 76.5 & 2 & 0.33 ef & 91.0 & 0.5 \\
\hline & 4 & $2.7 \mathrm{~g}$ & 91.3 & 1.5 & 0.33 ef & 91.0 & 0.5 \\
\hline \multirow[t]{3}{*}{ Peach } & 1 & $8.0 \mathrm{~d}$ & 74.2 & 2 & $1.00 \mathrm{de}$ & 72.8 & 1 \\
\hline & 2 & $6.7 \mathrm{de}$ & 78.4 & 2 & $0.0 f$ & 100 & 0 \\
\hline & 4 & $3.0 \mathrm{fg}$ & 90.3 & 2 & $0.0 f$ & 100 & 0 \\
\hline \multirow[t]{3}{*}{ Plum } & 1 & $11.7 \mathrm{c}$ & 62.3 & 3 & $2.33 b$ & 36.5 & 2 \\
\hline & 2 & 5.3def & 82.9 & 2 & $2.00 \mathrm{bc}$ & 45.5 & 1 \\
\hline & 4 & $3.3 f g$ & 89.4 & 2 & 0.33 ef & 91.0 & 0.5 \\
\hline \multicolumn{2}{|l|}{ Oxamyl } & $0.0 \mathrm{~h}$ & 100 & 0 & $0.0 f$ & 100 & 0 \\
\hline \multicolumn{2}{|l|}{$\mathrm{N}$ alone } & $31.0 a$ & $\begin{array}{ll}--- \\
\end{array}$ & 4 & $3.67 a$ & --- & 2 \\
\hline
\end{tabular}

$\mathrm{N}=1000 \mathrm{~J} 2$ of $M$. incognita

*Each figure represented the mean of three replicates.

Means in each column followed by the same letter(s) did not significantly differ at $(P<.05)$ according to Duncan's multiple range test.

${ }^{\star \star} \mathrm{RGI}=$ Root gall index and ${ }^{\star * \star} \mathrm{El}=$ Eggmass index according to Taylor and Sasser (1978). 
Refaei, A.R.

Moreover, improvement in growth parameters of the nematode-infected plants has been achieved due to the application of the tested fruit seed kernel contents, however, apricot fresh kernel in spite of its suppressive effect on nematode parameters (95.8 \& 100\%) and surpassed product of peach kernel content, it ranked third to the tested fresh peach materials in improving okra plants growth characters i.e. (110.6\% \& 110.7\%) for total plant fresh weight and shoot dry weight, respectively. Meanwhile, peach either dry or fresh kernel content with its vitamin $\mathrm{E}$ and fatty acids suppressed number of galls and eggmasses with values of $90.3 \& 100 \%$ each, a situation which agreed with the finding of Saeed (2005), who reported that the deposited eggs leggmass in treatments of vitamin $\mathrm{E}$ were significantly decreased when compared with that of the check, and he also said that number of galls were positively proportional to concentration levels of vitamin $\mathrm{E}$. These results are also in accordance with those of Montasser (1991) and Refaei (2009) in respect to vitamins. These findings are also in conformity with those of Zahir(2004) in respect to the essential fatty acids of sesame oil against $M$. incognita on sunflower. Essential oil of such oil-seed-cakes products may disrupt the cell membrane of the nematode and change its permeability (Oka et al., 2000). Moreover, results of this work also prove that such fruit products as seed kernel contents may participate in inducing resistant in susceptible plants to the target nematode pests.

In conclusion, results of the present work draw the attention to the possible utilization of such products of the tested fruit seed kernels in producing a safety novel biocide as a new trend in managing such nematode pests. However, additional experiments may also needed to be done to determine the beneficial effects of such fruit seed kernel products instead of removing them away as waste materials that will increase environmental pollution.

\section{REFERENCES}

Akhtar, M. and M. M. Alam, (1989). Evaluation of nematicidal potential in some medicinal plants. Int. Nematol. Network Newsl., 6(1) : 8-10.

Anke, H. M. and T. A. Stadler (1995). Secondary metabolites with nematicidal and antimicrobial activity from nematophagus fungi and Ascomycetes. Canadian J. Botany, 73 : 5932-5939.

Badra, T.; M. A. Saleh; and B. A. Otiefa, (1979). Nematicidal activity and composition of some organic fertilizers and amendments. Revue de Nematologie, 2(1): 29-36.

Duncan, D.B. (1955). Multiple range and multiple, F-test. Biometrics, 11: 142.

Errico, F. P. D. and F. Di. Maio, (1980). Effects of some organic materials on root-knot nematodes on tomatoes in filed preliminary experiments. Nematol. Medit., $8:$ 107- 110.

Farahat, A. A. ; H. H. Hendy; H. I. El-Nagar, and A. El-Ghonemy, (1994). Time of application of dry ground leaves in relation to the reniform nematode reproduction on sunflower. Egypt. J. Appl. Sci., 9:79-97. 
Guilt, P.; C. Lear; D. Birt ; M. Tempero; A. Grandjean; P. Raddon ; and D. Nagel (1993). Nematicidial properties of garlic Allium sativa L. Indian J. of Nematol., 21(1): 14-18.

Gomez, K. A. and A.A. Gomez (1984). Statistical Procedures for Agricultural Research. $2^{\text {nd }}$ Ed., John Wiley \&Sons. Inc., New York.

Goodey, J.B. (1957). Laboratory methods for work with plant and soil nematodes. Tech. Bull. No. 2. Min. Agric. Fish Ed. London, $47 \mathrm{pp}$.

Khalil, A. E. M. (2000). Integrated control of reniform nematode on certain plant crops. Ph. D. Thesis, Fac. Agric., Mansoura Univ.124 pp.

Latif, Z. H ; R.Ahmed ; V. I. Inam; and M. Hag (1999). Effect of seed treatments with neem cake, neem oil and latex of oak on the germination of cowpea and its vulnerability to root-knot nematode (Meloidogyne incognita). Pakistan J. Phytopathol. , 11(1) : 52-55.

Montasser, S. A. (1991). Effect of decomposing dry leaf powders on the incidence of root galls and growth of tomato. Ann. J. Agric. Sci. Moshtohor, 29:1739-1750.

Oka, Y. ; S. Nacar; E. putievsky; V. Ravid; Z. Yaniv and V. Spiegel (2000). Nematicidal activity of essential oils and their components against the root-knot nematode. Phytopathology, 90(7) : 710-715

Picuric-jovanovic, K. and M. Milovanovic (1993). Analysis of volatile compounds in almond and plum kernel oils. JAOCS, 70 (11): 11011104.

Refaei, A. R.,(2009). Suppressive effects of certain vitamins and organic acids against Meloidogyne incognita on okra plant and their role in improving host growth under greenhouse conditions. J. Agric. Sci. Mansoura Univ., 34(3):2183-2190.

Refaei, A. R.; A. G.El-Sherif; M. E. El-Nagar; and H. A. El-Ghanam (2008). Controlling Tylenchulus semipenetrans infecting sour-orange plants by plant extracts and oxamyl. Egypt. J. Agronematol., 6(1) : 75-85.

Rodriguez-Kabana, R. (2000). Comparative study on the nematicidal activities of garlic and mustard oils. Annual International Research Conference on Methyl Bromide Alternative and Emissions Reductions, Auburn Univ.

Saeed, M. R. M. (2005). Utilization of some specific materials to stimulate resistance in some host plants against the root knot nematodes. Ph. D. Thesis, Fac. Agric., Cairo Univ., 220 pp.

Schneider, E. (1985). Pharmaceutice Biologie, Bibliographisches, Institute, Manheim Wirn, Zurich.

Sitaramaiah, K. and R.S. Singh, (1978). Effect of organic amendments on phenolic content of soil and plant, and response of Meloidogyne incognita and its host to related compound. Plant and Soil , 50: 671679.

Someya, K. ; S. Mikoshiba; T. Okumura; H. Takenaka; M. Ohdera; O. Shirota and M. Kuroyanagi (2006). Suppressive effect of constituents isolated from kernel of Prunus armeniaca on 5 a-androst-16-en-3-one generated by microbial metabolism. J. Oleo. Sci., 55: 353-364. 
Refaei, A.R.

Taylor, A. L. ; and J. N. Sasser (1978). Biology, identification and control of root-knot nematodes (Meloidogyne species). Coop. Publ. Dept. Plant Pathol., North Carolina State Univ. and U.S. Agency for Int. Dev. , Raleigh, N. C. $111 \mathrm{pp}$.

Zahir, Gehan, A. M. (2004). Controlling root-knot nematodes by certain plant extracts. M. Sc. Thesis, Agric. Zool. Dept., Fac. Agric., Mansoura Univ. 99pp.

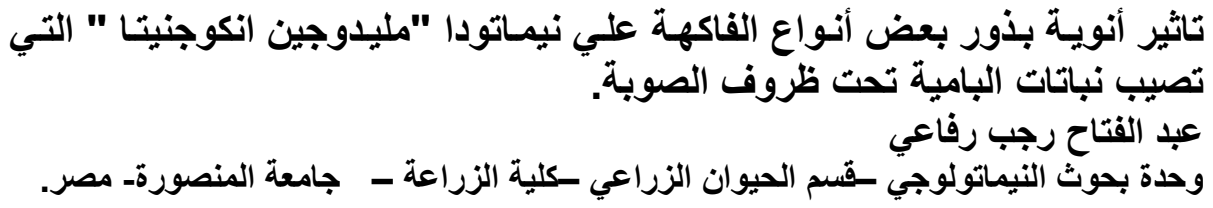

تم إجر اء هذة التجربة في الصوبة بغرض معرفة تأثير أنوية بذور ثناثتة نباتات فاكهة و هي واكي

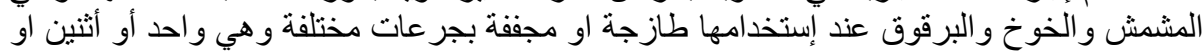

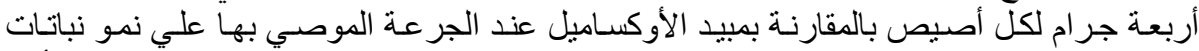

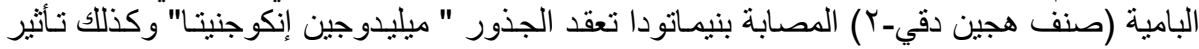

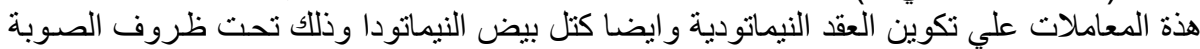

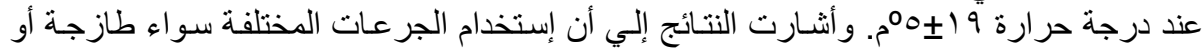

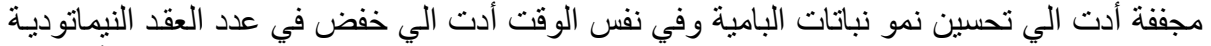

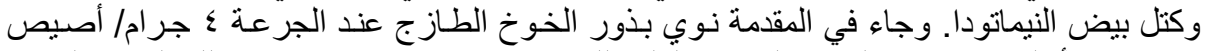

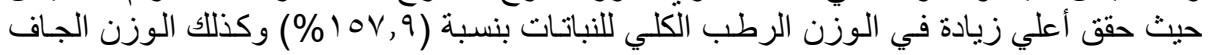

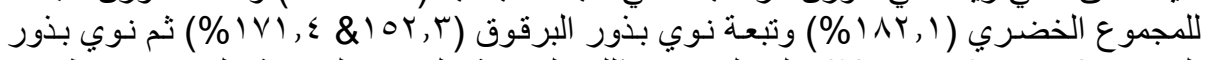

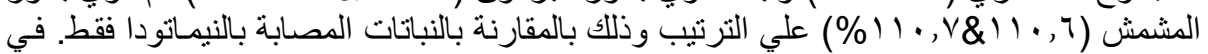

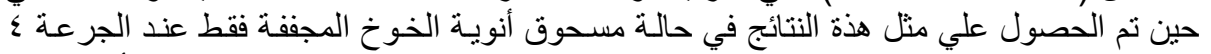

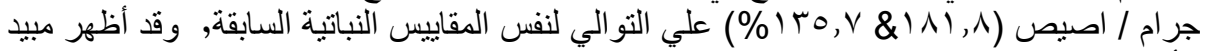

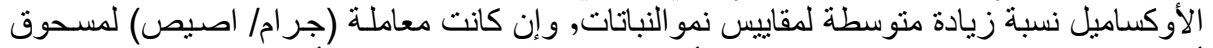

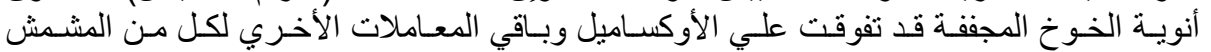

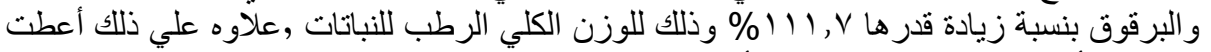

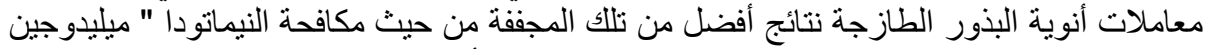

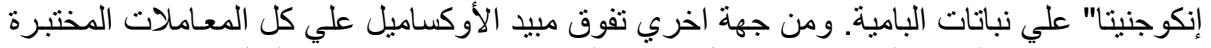

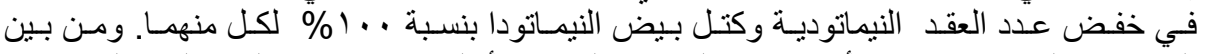

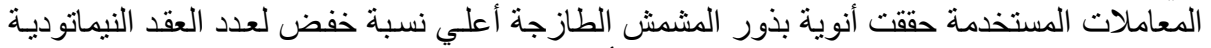

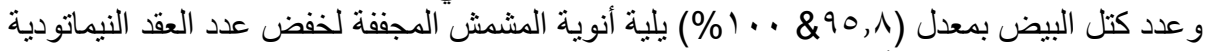

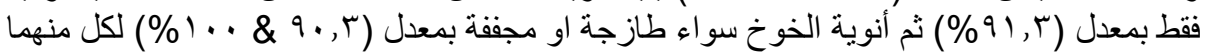

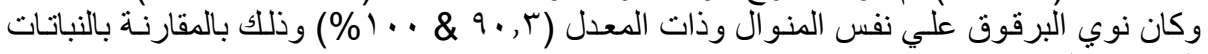

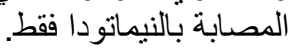


Table 1: Plant growth response of okra infected with Meloidogyne incognita as affected by adding fresh kernel powders of three different fruit seeds kernels conditions.

\begin{tabular}{|c|c|c|c|c|c|c|c|c|c|c|c|}
\hline \multirow{3}{*}{$\begin{array}{l}\text { Treatments } \\
\text { (Fresh seed } \\
\text { kernels) }\end{array}$} & \multirow{3}{*}{ Doses (gm) } & \multicolumn{10}{|c|}{${ }^{*}$ Plant growth response } \\
\hline & & \multicolumn{4}{|c|}{ Length $(\mathrm{cm})$} & \multicolumn{4}{|c|}{ Fresh weight (gm) } & \multicolumn{2}{|c|}{ Dry weight (gm) } \\
\hline & & Shoot & Root & Total & Inc. \% & Shoot & Root & Total & Inc. \% & Shoot & Inc. $\%$ \\
\hline \multirow{3}{*}{ Apricot } & 1 & $31.0 \mathrm{~d}$ & $29.6 \mathrm{bcd}$ & 60.6 & 30.8 & $3.20 \mathrm{ef}$ & $0.79 \mathrm{e}$ & 3.99 & 51.1 & $0.40 \mathrm{de}$ & 42.9 \\
\hline & 2 & $36.0 \mathrm{~b}$ & $32.3 \mathrm{bc}$ & 68.3 & 47.5 & $3.62 d$ & $0.91 \mathrm{de}$ & 4.53 & 71.6 & $0.42 \mathrm{de}$ & 50.0 \\
\hline & 4 & $38.0 \mathrm{a}$ & $43.6 a$ & 81.6 & 76.2 & $4.42 \mathrm{c}$ & $1.14 \mathrm{~cd}$ & 5.56 & 110.6 & $0.59 \mathrm{c}$ & 110.7 \\
\hline \multirow{3}{*}{ Peach } & 1 & 30.3de & $30.0 \mathrm{bcd}$ & 60.3 & 30.2 & $3.16 \mathrm{ef}$ & $1.21 \mathrm{c}$ & 4.37 & 65.5 & $0.48 d$ & 71.4 \\
\hline & 2 & $34.0 \mathrm{c}$ & 28.3cde & 62.3 & 34.6 & $3.59 d$ & $1.29 \mathrm{bc}$ & 4.88 & 84.8 & $0.58 \mathrm{c}$ & 107.1 \\
\hline & $\overline{4}$ & $39.3 a$ & \begin{tabular}{|l}
$30.7 \mathrm{bcd}$ \\
\end{tabular} & 70.0 & 51.1 & $5.33 a$ & $1.48 \mathrm{~b}$ & 6.81 & 157.9 & $0.79 a$ & 182.1 \\
\hline \multirow{3}{*}{ Plum } & 1 & $21.3 f$ & $28.0 \mathrm{cde}$ & 49.3 & 6.5 & $2.80 f$ & $1.39 \mathrm{bc}$ & 4.19 & 58.7 & $0.36 \mathrm{ef}$ & 28.6 \\
\hline & 2 & $35.0 \mathrm{bc}$ & \begin{tabular}{|l}
$32.0 \mathrm{bcd}$ \\
\end{tabular} & 67.0 & 44.7 & $4.20 \mathrm{c}$ & $1.28 \mathrm{bc}$ & 5.48 & 107.6 & $0.66 \mathrm{bc}$ & 135.7 \\
\hline & 4 & $36.0 \mathrm{~b}$ & \begin{tabular}{|l|}
$34.6 b$ \\
\end{tabular} & 70.6 & 52.5 & $4.90 \mathrm{~b}$ & $1.76 a b$ & 6.66 & 152.3 & $0.76 a b$ & 171.4 \\
\hline \multicolumn{2}{|l|}{ Oxamyl } & $35.0 \mathrm{bc}$ & $40.0 \mathrm{a}$ & 75.0 & 61.9 & 3.37de & $1.95 a$ & 5.32 & 101.5 & $0.44 \mathrm{de}$ & 57.1 \\
\hline \multirow{2}{*}{\multicolumn{2}{|c|}{\begin{tabular}{|l}
$\mathrm{N}$ alone \\
Plant free of
\end{tabular}}} & $22.3 f$ & 24.0ef & 46.3 & --- & $1.96 \mathrm{~g}$ & $0.68 \mathrm{e}$ & 2.64 & -- & $0.28 f$ & --- \\
\hline & & 30.0de & 27.0de & 57.0 & 23.1 & $2.12 \mathrm{fg}$ & $0.83 \mathrm{e}$ & 2.95 & 11.7 & $0.34 \mathrm{ef}$ & 21.4 \\
\hline
\end{tabular}

$\mathrm{N}=1000 \mathrm{~J} 2$ of $M$. incognita

${ }^{\star}$ Each figure represented the mean of three replicates.

Means in each column followed by the same letter(s) did not significantly differ at $(P<.05)$ according to Duncan's multiple range test.

Table 2: Plant growth response of okra infected with Meloidogyne incognita as affected by adding dried kernel powders of three different fruit seeds kernels in comparison with oxamyl under greenhouse conditions.

\begin{tabular}{|c|c|c|c|c|c|c|c|c|c|c|c|}
\hline \multirow{3}{*}{$\begin{array}{c}\text { Treatments (Dried seed } \\
\text { kernels) }\end{array}$} & \multirow{3}{*}{$\begin{array}{c}\text { Doses } \\
\text { (gm) }\end{array}$} & \multicolumn{10}{|c|}{ * Plant growth response } \\
\hline & & \multicolumn{4}{|c|}{ Length (cm) } & \multicolumn{4}{|c|}{ Fresh weight (gm) } & \multicolumn{2}{|c|}{ Dry weight (gm) } \\
\hline & & Shoot & Root & Total & Inc. \% & Shoot & Root & Total & Inc. \% & Shoot & Inc. $\%$ \\
\hline \multirow{3}{*}{ Apricot } & 1 & $29.0 \mathrm{e}$ & $30.7 \mathrm{~b}$ & 59.7 & 28.9 & $2.62 d$ & $0.78 \mathrm{ef}$ & 3.40 & 28.8 & $0.33 \mathrm{de}$ & 17.9 \\
\hline & 2 & $30.0 \mathrm{de}$ & $32.5 b$ & 62.5 & 33.9 & $2.82 d$ & $0.79 \mathrm{ef}$ & 3.61 & 36.7 & $0.50 \mathrm{~b}$ & 78.5 \\
\hline & 4 & $32.7 \mathrm{~cd}$ & $44.0 \mathrm{a}$ & 76.7 & 65.6 & $3.40 \mathrm{c}$ & $1.49 \mathrm{bc}$ & 4.89 & 85.2 & $0.63 a$ & 125.0 \\
\hline \multirow{3}{*}{ Peach } & 1 & $37.6 \mathrm{c}$ & $30.0 \mathrm{~b}$ & 67.6 & 46.0 & $4.04 \mathrm{~b}$ & $1.55 \mathrm{bc}$ & 5.59 & 111.7 & $0.50 \mathrm{~b}$ & 78.6 \\
\hline & 2 & $40.0 \mathrm{~b}$ & $31.0 \mathrm{~b}$ & 71.0 & $53 . .3$ & $4.11 \mathrm{~b}$ & $1.68 \mathrm{~b}$ & 5.79 & 119.3 & $0.65 a$ & 132.1 \\
\hline & 4 & $41.0 \mathrm{~b}$ & $34.0 \mathrm{~b}$ & 75.0 & 61.9 & $5.09 a$ & $2.35 a$ & 7.44 & 181.8 & $0.66 \mathrm{a}$ & 135.7 \\
\hline \multirow{3}{*}{ Plum } & 1 & $32.3 \mathrm{~cd}$ & $26.0 \mathrm{bc}$ & 58.3 & 25.9 & $2.76 \mathrm{~d}$ & $1.00 \mathrm{de}$ & 3.76 & 42.4 & $0.35 d$ & 25.0 \\
\hline & 2 & $32.6 \mathrm{~cd}$ & $27.3 \mathrm{bc}$ & 59.9 & 29.4 & $3.33 c$ & $1.24 \mathrm{~cd}$ & 4.57 & 73.1 & $0.40 \mathrm{~cd}$ & 42.8 \\
\hline & 4 & $48.6 a$ & $33.3 \mathrm{~b}$ & 81.9 & 76.8 & $3.33 c$ & $1.36 \mathrm{c}$ & 4.69 & 77.6 & $0.42 \mathrm{~cd}$ & 50.0 \\
\hline \multicolumn{2}{|c|}{ Oxamyl } & $35.0 c$ & $40.0 \mathrm{a}$ & 75.0 & 61.9 & $3.37 c$ & $1.95 a b$ & 5.32 & 101.5 & $0.44 \mathrm{C}$ & 57.1 \\
\hline \multirow{2}{*}{\multicolumn{2}{|c|}{$\begin{array}{l}\mathrm{N} \text { alone } \\
\text { Plant free of } \mathrm{N} \text { and untreated }\end{array}$}} & $22.3 f$ & $24.0 \mathrm{c}$ & 46.3 & --- & $1.96 \mathrm{e}$ & $0.68 \mathrm{f}$ & 2.64 & -- & $0.28 \mathrm{e}$ & \\
\hline & & $30.0 \mathrm{de}$ & $27.0 \mathrm{bc}$ & 57.0 & 23.1 & $2.12 \mathrm{de}$ & 0.83 ef & 2.95 & 11.7 & $0.34 d$ & 21.4 \\
\hline
\end{tabular}

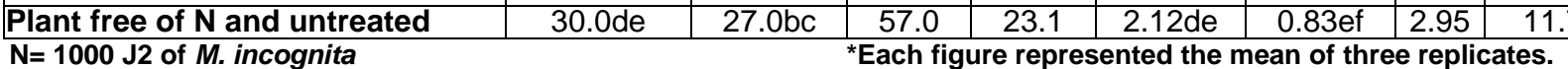

Means in each column followed by the same letter(s) did not significantly differ at $(P<.05)$ according to Duncan's multiple range test. 